Supplemental information to the manuscript:

\title{
Loading Polyelectrolytes onto Porous Microspheres: Impact of Molecular and Electrochemical Parameters
}

\author{
Vesela Malinova and Christine Wandrey*
}

École Polytechnique Fédérale de Lausanne, Institut de Bioingénierie

$\mathrm{CH}$

- 1015 Lausanne, Switzerland

The supporting information provides additional experimental results. These results are complementary and do not present any novel finding or facts exceeding the principal information of the paper. 
Nevertheless, the results obtained for an extended experimental range may be of interest for some readers. Moreover, they can be taken as further justification of the discussion and conclusions.

- Figure S1 confirms for A-25 on $\mathrm{MS}^{6} 0^{6}$ the absence of ionic strength influence in the investigated range

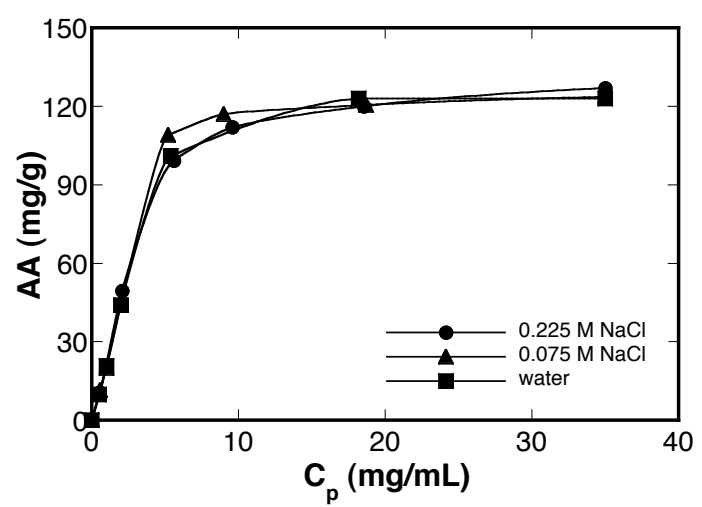

Figure S1. Influence of the ionic strength. Adsorbed amount as a function of the initial polyelectrolyte concentration. A- 25 on $\mathrm{MS} 10^{6}, \mathrm{~T}=25^{\circ} \mathrm{C}$.

- Figure S2 demonstrates the influence of the substituents for loading onto MS10 .

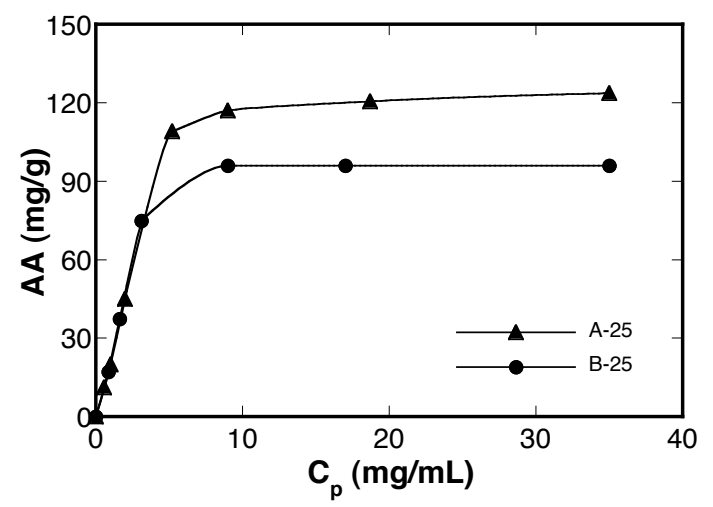

Figure S2. Influence of the substituents at the ionic group. Adsorbed amount as a function of the initial polyelectrolyte concentration in $0.075 \mathrm{M} \mathrm{NaCl} . \mathrm{MS}_{10} 0^{6} \mathrm{~T}=25^{\circ} \mathrm{C}$.

- Figure S3 confirms the influence of the substituents for loading onto MS10 6 at higher ionic strength than in Figure S2. 


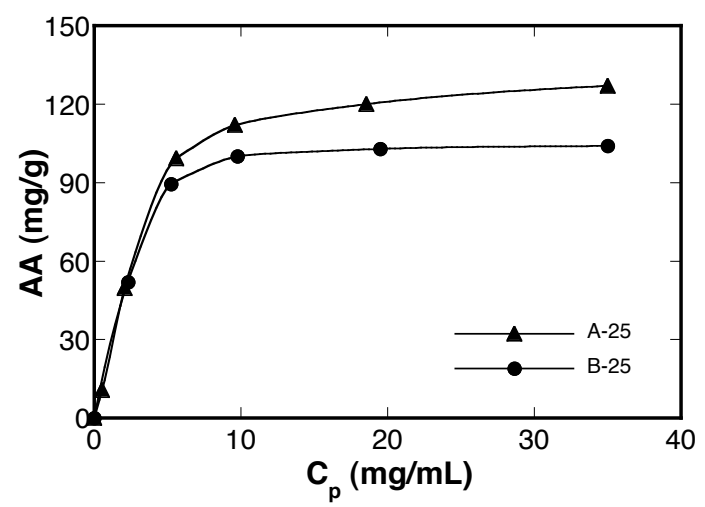

Figure S3. Influence of the substituents at the ionic group. Adsorbed amount as a function of the initial polyelectrolyte concentration in $0.225 \mathrm{M} \mathrm{NaCl} . \mathrm{MS}_{10}, \mathrm{~T}=25^{\circ} \mathrm{C}$.

- Figure S4 demonstrates faster equilibration of A-25 on MS10 ${ }^{6}$ compared to MS10 ${ }^{3}$.

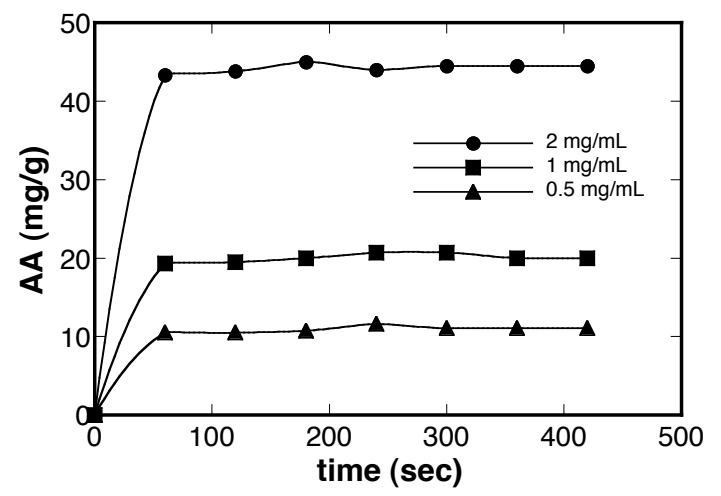

Figure S4. Adsorbed amount as a function of time for different initial polyelectrolyte concentrations and $\mathrm{MS}_{10}{ }^{6}$ in $0.075 \mathrm{M} \mathrm{NaCl} . \mathrm{A}-25, \mathrm{~T}=25^{\circ} \mathrm{C}$.

- Figure S5 presents an example that the adsorption on MS with $5 \mu \mathrm{m}$ diameter was not significantly different compared to $10 \mu \mathrm{m}$ diameter under otherwise same conditions. (Compare with Figure 4b.) 


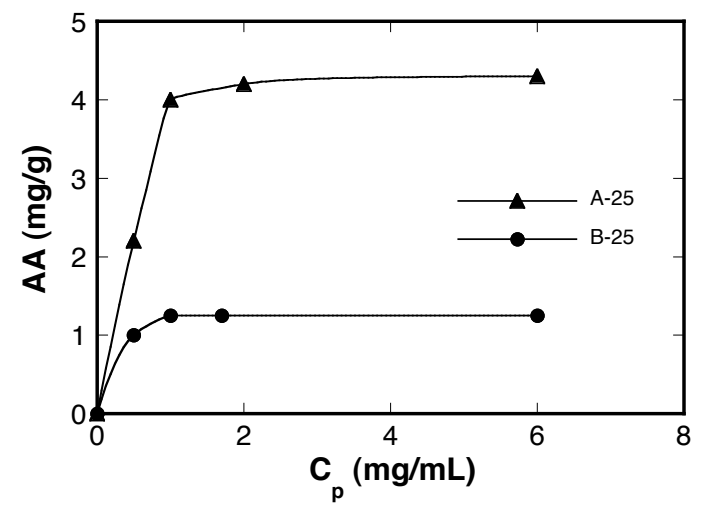

Figure S5. Influence of the substituents at the ionic group. Adsorbed amount as a function of the initial polyelectrolyte concentration in $0.075 \mathrm{M} \mathrm{NaCl}$. $\mathrm{MS}_{10}{ }^{2}$ but diameter $5 \mu \mathrm{m}, \mathrm{T}=25^{\circ} \mathrm{C}$. 